\title{
Degradation of octylbenzene sulfonate photoinduced by iron(III) aquacomplexes: Evidence for the fragmentation of the alkyl chain
}

\author{
Nadra Debbache, ${ }^{1,2}$ Gilles Mailhot, ${ }^{2}$ Kamel Djebbar, ${ }^{1}$ Bernadette Lavedrine, ${ }^{2}$ \\ and Michèle Bolte ${ }^{2, \dagger}$ \\ ${ }^{1}$ Laboratoire des Sciences et Technologies de l'Environnement, Université de Mentouri, 25000 Constantine, Algeria \\ ${ }^{2}$ Laboratoire de Photochimie Moléculaire et Macromoléculaire, Université Blaise Pascal, UMR CNRS 6505, \\ F-63177 Aubière Cedex, France
}

\begin{abstract}
The degradation of octylbenzene sulfonate (OBS) photoinduced by iron(III) aquacomplexes was investigated upon irradiation at $365 \mathrm{~nm}$ and by solar light. The photochemical degradation appears to be due to $\mathrm{HO}^{\bullet}$ radicals arising from the electron transfer in $\mathrm{Fe}(\mathrm{OH})^{2+}$. If oxygen does not affect the initial quantum yield of OBS degradation, it is necessary to pursue the reaction up to, first the complete disappearance of OBS and secondly OBS mineralization. The nature of the major photoproducts gives evidence for a competitive attack of $\mathrm{HO}^{\bullet}$ radicals on the alkyl chain resulting in a shortening of the chain. Among the possible sites on the chain, hydrogen on the carbon in $\alpha$ position with respect to the aromatic ring was the main point of attack with the formation of 4-acetylbenzene sulfonate and 4-carboxylicbenzene sulfonate.
\end{abstract}

\section{INTRODUCTION}

One of the most common types of aqueous surfactants is the linear alkylbenzenze sulfonate family (LAS). LAS are anionic surfactants widely used for the production of detergents and household cleaners [1]. The worldwide consumption of LAS was estimated at 1.5 to 2 million tons per year [2]. Among the LAS-type surfactants used in household detergents, 4-dodecylbenzene sulfonate (DBS) is the most representative one.

Laboratory and environmental studies indicate LAS to be ultimately biodegraded at acceptably high rates under aerobic conditions [3]. However, during sewage treatment a portion (10\% or more) of LAS, which is adsorbed onto sewage solids, is removed during primary settlement of sewage and will not undergo normal aerobic treatment [4]. The resulting sludge is generally digested under anaerobic conditions and LAS is not degraded under these conditions. So it often occurs in high concentration in sewage sludge (median concentration $530 \mathrm{mg} \mathrm{kg}^{-1}$ dry weight) [5]. Because sewage sludge is widely used as a fertilizer of agricultural soils, LAS is introduced into the environment by this way. Whereas the risk assessment of LAS in the aquatic and terrestrial environment is low [6], LAS is potentially harmful to living organisms because of surface-active abilities, which may disrupt membranes and cause proteins to denature [7]. Moreover, the nature and toxicity of their metabolites could be a real problem for the environment. In fact, the biodecomposition of LAS often leads to the formation of more persistent and even more toxic metabolites.

\footnotetext{
†E-mail: michele.bolte@univ-bpclermont.fr
}

Degradation by light, reaction with hydroxyl radicals $\mathrm{HO}^{\bullet}$ and hydrolysis are the principal processes of abiotic pollutant degradation in the environment and can provide an alternative way to biodegradation. The major abiotic reactions (except the hydrolysis) are connected with irradiation by sunlight. If the pollutant does not absorb solar light, its transformation can be photoinduced by different absorbing species present or added in the aquatic medium (nitrate [8], humic substances [9], iron(III) complexes [10], ... ). The common point of these species is the formation under irradiation of highly oxidative species, mainly hydroxyl radicals $\mathrm{HO}^{\bullet}$, which degrade many organic compounds in water with rate constants close to that of diffusion controlled process [11].

The formation of these oxidative species has been used in different chemical processes, designated as advanced oxidation processes (AOPs), to eliminate organic compounds in aqueous contaminated solutions. During the ninety's, different groups extensively reported on the advanced oxidation processes (AOP's) for the decomposition of LAS and more particularly on the photodegradation processes [12]. Several papers deal with the photoinduced catalytic decomposition of surfactants. The efficiency of the photocatalytic degradation of these compounds by using $\mathrm{TiO}_{2}$ particles was very well established. For aromatic surfactants like LAS derivatives, the aromatic ring was reported to decompose more rapidly than the alkyl chain [13]. The mechanism involved the attack of the surfactants by $\mathrm{HO}^{*}$ radicals followed by further degradation into $\mathrm{CO}_{2}(\mathrm{~g})$ and $\mathrm{SO}_{4}{ }^{2-}$ ions. 
Among AOP's, the process of homogeneous photocatalysis based on iron(III) in aqueous solution, has been studied for more than ten years in our laboratory and we already reported the efficiency of iron(III) aquacomplexes for the photogeneration of hydroxyl radicals and thus for pollutant degradation [10, 14-16]. Among the iron(III) aquacomplexes, $\mathrm{Fe}(\mathrm{OH})^{2+}$ (which refers to $\left.\left[\mathrm{Fe}(\mathrm{OH})\left(\mathrm{H}_{2} \mathrm{O}\right)_{5}\right]^{2+}\right)$ is known $[17,18]$ as being photolysed with the highest quantum yield of the reaction:

$$
\mathrm{Fe}(\mathrm{OH})^{2+} \stackrel{\mathrm{h} v}{\longrightarrow} \mathrm{Fe}^{2+}+\mathrm{HO}^{\bullet}
$$

This electron transfer process was used to achieve the degradation of several pollutants in aqueous solution and in most cases, the total mineralization of the pollutant was observed thanks to the redox cycle $\mathrm{Fe}^{3+} / \mathrm{Fe}^{2+}[19]$.

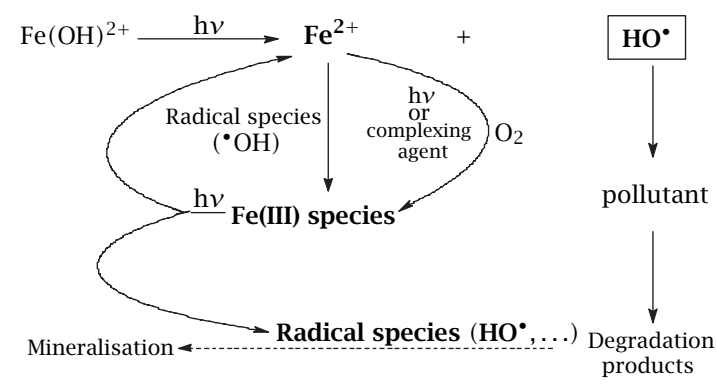

A previous work study was carried out on the degradation of sodium 4-dodecylbenzene sulfonate (DBS) photoinduced by iron(III) in aqueous solution [20]. The primary step of the decomposition of DBS appeared to mainly involve a hydrogen abstraction on the carbon atom in the $\alpha$ position of the aromatic ring but the photoreaction was accompanied by a complex phenomenon of flocculation provoked by the addition of iron(III). The photodegradation of DBS was efficiently achieved, for long irradiation times the total disappearance of DBS and of the aromatic photoproducts was observed. However, the commercial product used in this study was a mixture of various alkyl homologues $\left(\mathrm{C}_{10^{-}}\right.$ $\mathrm{C}_{14}$ ) and phenyl positional isomers. It is usually a mixture of at least 19 different compounds, which made the mechanistic approach and the chemical analysis of the photoproducts very difficult if not impossible. Moreover, the complete mineralization of DBS was not controlled during this former work.

For these reasons, the use of a pure LAS derivative was considered. Accordingly, OBS (octylbenzene sulfonate) degradation photoinduced by iron(III) aquacomplexes was investigated from the primary reactions to the complete mineralization and is reported in the present paper.

\section{MATERIALS AND METHODS}

2.1. Chemicals. Sodium 4-n-octylbenzene sulfonate (OBS) (99\%) was purchased from Lancaster and used without further purification. 8-hydroxyquinoline5-sulfonic acid monohydrate (HQSA; 98\%) was purchased from Aldrich. Ferric perchlorate nonahydrate $\left[\mathrm{Fe}\left(\mathrm{ClO}_{4}\right)_{3} 9 \mathrm{H}_{2} \mathrm{O}, 97 \%\right]$ was a Fluka product and Ferrous perchlorate $\left[\mathrm{Fe}\left(\mathrm{ClO}_{4}\right)_{2} \times \mathrm{H}_{2} \mathrm{O}, 98 \%\right]$ was an Aldrich product, both kept in a dessicator. Solutions of iron(III) used for the studies $\left(3 \times 10^{-4} \mathrm{~mol} \mathrm{~L}^{-1}\right)$, were prepared by diluting stock solutions of $\mathrm{Fe}\left(\mathrm{ClO}_{4}\right)_{3}, 9 \mathrm{H}_{2} \mathrm{O}$ $\left(2.0 \times 10^{-3} \mathrm{~mol} \mathrm{~L}^{-1}\right)$ to the appropriate iron(III) concentration. 2-Propanol and acetonitrile were HPLC grade products and purchased from Merck and Carlo Erba respectively.

All solutions were prepared with deionized ultrapure water $(\rho=18.2 \mathrm{M} \Omega \mathrm{cm}$ ). The $\mathrm{pH}$ of solution was adjusted by sodium hydroxyde and perchloric acid. When necessary, the solutions were deoxygenated at room temperature either by argon bubbling for $30 \mathrm{~min}$ in $5 \mathrm{~mL}$ quartz cell or by continuous nitrogen bubbling in the reactor used for irradiation $(100 \mathrm{~mL})$. We checked that there was no elimination of OBS during the bubbling.

2.2. Apparatus. In order to measure the quantum yields, monochromatic irradiations at 365, 334, and $313 \mathrm{~nm}$ were carried out with a high-pressure mercury lamp (Osram HBO 200 W) equipped with a grating monochromator (Bausch and Lomb). The beam was parallel and the reactor was a cylindrical quartz cell of $2 \mathrm{~cm}$ path length. The light intensity was measured by ferrioxalate actinometry [21]: $\mathrm{I}_{0} 365 \mathrm{~nm} \approx 2.5 \times 10^{15}$, $\mathrm{I}_{0} 334 \mathrm{~nm} \approx 0.5 \times 10^{15}, \mathrm{I}_{0} 313 \mathrm{~nm} \approx 1.0 \times 10^{15}$ photons $\mathrm{s}^{-1} \mathrm{~cm}^{-2}$. The quantum yields were calculated for a reaction extent lower than $10 \%$.

In order to irradiate larger volume $(\mathrm{V}=60 \mathrm{~mL})$ at $\lambda_{\text {exc. }}=365 \mathrm{~nm}$, for kinetic and analytical experiments, an elliptical stainless steel reactor was used. A high-pressure mercury lamp enclosed in a glass filter bulb (Mazda HPW type $125 \mathrm{~W}$ ), whose emission consists of $93 \%$ of $365 \mathrm{~nm}$ (few percents of the light is emitted at 313, 334 and $405 \mathrm{~nm}$ ), was placed in one of the focal axes, while the photoreactor, a water-jacketed Pyrex tube (internal diameter $=2.8 \mathrm{~cm}$ ), was centered at the other one. The reaction medium was continuously stirred. Experiments in field conditions were performed in a Pyrex cylindrical reactor $(100 \mathrm{~mL})$ on a sunny day in July in Clermont-Ferrand (latitude $46^{\circ} \mathrm{N}, 400 \mathrm{~m}$ above sea level).

UV-Visible spectra were recorded on a Cary 3 double beam spectrophotometer.

HPLC experiments were carried out using a Waters chromatograph equipped with two pumps Waters 510, an auto-sampler Waters 717 and a Waters 996 photodiode array detector. The flow rate was $1 \mathrm{~mL} \mathrm{~min}{ }^{-1}$ 
and the eluent a mixture of water with $0.1 \mathrm{~mol} \mathrm{~L}^{-1}$ of $\mathrm{NaClO}_{4}$ and acetonitrile. The column was a Nucleodur (Macherey-Nagel) C18 (reverse phase) of $250 \times 4.6 \mathrm{~mm}$ with a particle diameter of $5 \mu \mathrm{m}$ and a pore diameter of $100 \AA$.

${ }^{1} \mathrm{H}$ NMR spectra were recorded on a Bruker AC $400 \mathrm{MHz}$ Fourier transform spectrometer.

2.3. Analysis. The method of measuring the monomeric concentration of iron(III) $\left(\mathrm{Fe}(\mathrm{OH})^{2+}\right.$ under our experimental conditions) was modified from Kuenzi's procedure [22] and described in our previous papers $[15,16]$. In this paper, the term "percentage of monomeric species $\mathrm{Fe}(\mathrm{OH})^{2+}$ " will be used, it is defined as:

$$
\% \mathrm{Fe}(\mathrm{OH})^{2+}=\frac{\left[\mathrm{Fe}(\mathrm{OH})^{2+}\right]}{\left[\mathrm{Fe}(\mathrm{III}) \mathrm{t}_{0}\right.} \times 100
$$

where $[\mathrm{Fe}(\mathrm{III})] \mathrm{t}_{0}$ is the total starting concentration of iron(III).

Iron(II) concentration was determined by complexometry with ortho-phenanthroline, using $\varepsilon_{510}=1.118 \times$ $10^{4} \mathrm{~L} \mathrm{~mol}^{-1} \mathrm{~cm}^{-1}$ for the iron(II)-phenanthroline complex [21].

The concentrations of OBS and its photoproducts were followed by HPLC analysis $\left(\lambda_{\text {detection }}=222 \mathrm{~nm}\right)$ with a mixture of water with $0.1 \mathrm{~mol} \mathrm{~L}^{-1}$ of $\mathrm{NaClO}_{4}$ and acetonitrile as eluent (v/v 60/40 and 90/10) respectively.

Total Organic Carbon measurements, based on the combustion of carbon detected by infrared gas analysis method, were followed with a TOC analyzer Shimadzu model TOC-5050A. The calibration curves within the range $1-15 \mathrm{mg} \mathrm{L}^{-1}$ were obtained by using potassium hydrogen phthalate and sodium hydrogen carbonate for organic and inorganic carbon, respectively. The threshold of detection is around $1.5 \mathrm{mg} \mathrm{L}^{-1}$.

\section{RESULTS AND DISCUSSION}

3.1. Characterisation of OBS and iron(III) in aqueous solution. Under our experimental conditions $1.0 \times 10^{-4}<[\mathrm{Fe}(\mathrm{III})]<1.0 \times 10^{-3} \mathrm{~mol} \mathrm{~L}^{-1}$ and $\mathrm{pH}$ ranging from 3.5 to $3, \mathrm{Fe}(\mathrm{OH})^{2+}$ is the predominant if not the only monomeric iron(III) aquacomplex [23]. However as previously reported [14-16], the speciation of iron(III) in aqueous solution changed with time due to hydrolysis and oligomerization processes. While the content of $\mathrm{Fe}(\mathrm{OH})^{2+}$ in a freshly prepared solution of $\mathrm{Fe}\left(\mathrm{ClO}_{4}\right)_{3}\left(3.0 \times 10^{-4} \mathrm{~mol} \mathrm{~L}^{-1}\right)$ was $100 \%$ approximately, it decreased to $30 \%$ after 1 hour by following a first order kinetics. This corresponds to the formation of oligomeric forms or soluble aggregates of iron(III) [24]. Unless otherwise noted, our experiments were performed at about $90 \%$ of $\mathrm{Fe}(\mathrm{OH})^{2+}$ with $[\mathrm{Fe}(\mathrm{III})]_{\text {total }}=3.0 \times 10^{-4} \mathrm{~mol} \mathrm{~L}^{-1}$.
Commercial NaOBS is pure at $99 \%$ and is highly soluble in water $\left(4.9 \mathrm{~g} \mathrm{~L}^{-1}\right.$ or $1.7 \times 10^{-2} \mathrm{~mol} \mathrm{~L}^{-1}$ at $\left.25^{\circ} \mathrm{C}\right)$. The structure was demonstrated by NMR spectroscopy. It presents a linear alkyl chain without ramification with phenyl ring bounded on the first carbon.

${ }^{1} \mathrm{H}$ NMR spectrum $\left(\mathrm{D}_{2} \mathrm{O}\right), \delta(\mathrm{ppm}): 7.69\left(2 \mathrm{H}, \mathrm{d}\left(\mathrm{J}_{2-3}=\right.\right.$ $8.2 \mathrm{~Hz}), \mathrm{H}_{2}$ et $\left.\mathrm{H}_{6}\right), 7.37\left(2 \mathrm{H}, \mathrm{d}\left(\mathrm{J}_{3-2}=8.2 \mathrm{~Hz}\right), \mathrm{H}_{3}\right.$ et $\left.\mathrm{H}_{5}\right)$, $2.67\left(2 \mathrm{H}, \mathrm{t}\left(\mathrm{J}_{7-8}=7.5 \mathrm{~Hz}\right), \mathrm{H}_{7}\right), 1.61\left(2 \mathrm{H}, \mathrm{s}, \mathrm{H}_{8}\right), 1.24$ $\left(10 \mathrm{H}, \mathrm{s}, \mathrm{H}_{9}\right.$ to $\left.\mathrm{H}_{13}\right), 0.83\left(3 \mathrm{H}, \mathrm{t}\left(\mathrm{J}_{14-13}=6.6 \mathrm{~Hz}\right), \mathrm{H}_{14}\right)$.

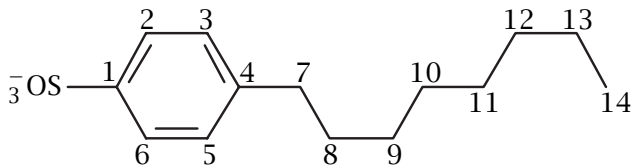

OBS

The usual concentration in OBS used in this work $\left(1.0 \times 10^{-4} \mathrm{~mol} \mathrm{~L}^{-1}\right)$ was much lower than the critical micelle concentration $(\mathrm{CMC})$ reported in the literature $\left(1.14 \times 10^{-2} \mathrm{~mol} \mathrm{~L}^{-1}\right.$ at $\left.25^{\circ} \mathrm{C}\right)$ [25]. NaOBS is stable in aqueous solution, no degradation was observed in the dark and at room temperature after 1 month. The UVvisible spectrum of OBS in aqueous solution presents two maximums, $222 \mathrm{~nm}\left(\varepsilon=12800 \mathrm{~L} \mathrm{~mol}^{-1} \mathrm{~cm}^{-1}\right)$ and $260 \mathrm{~nm}\left(\varepsilon=600 \mathrm{~L} \mathrm{~mol}^{-1} \mathrm{~cm}^{-1}\right)$.

A mixture of OBS and iron(III) was not stable in the dark and at room temperature in terms of both concentrations, OBS and $\mathrm{Fe}(\mathrm{OH})^{2+}$. A complicated thermal phenomenon, starting by a complexation process, leading to flocculation and oxydoreduction, was observed again and will be the subject of a paper in preparation [26]. However contrary to what was observed in the previous work with LAS, the time scale of these processes, apart from the complexation process roughly corresponding to $20 \%$ OBS disappearance, is much larger than the time of irradiation used during the study. Accordingly, the monitoring of the degradation was processed without further separation.

3.2. Degradation of OBS photoinduced by iron(III). OBS does not absorb at wavelengths higher than $300 \mathrm{~nm}$; there was no degradation when OBS was irradiated alone at $365 \mathrm{~nm}$ or by solar light. Irradiation of the mixture OBS $\left(1.0 \times 10^{-4} \mathrm{~mol} \mathrm{~L}^{-1}\right)$ and iron(III) $\left(3.0 \times 10^{-4} \mathrm{~mol} \mathrm{~L}^{-1}\right)$ was first carried out with about $90 \%$ of monomeric species $\mathrm{Fe}(\mathrm{OH})^{2+}$ in aerated conditions and at $365 \mathrm{~nm}$. The concentration of OBS continuously decreased and the complete degradation was reached within 4 hours (Figure 1).

3.2.1. Irradiation in the presence of 2-propanol. The photodegradation of OBS can be directly attributed to the attack of $\cdot \mathrm{OH}$ radicals as demonstrated by the inhibition of the degradation during irradiation at $365 \mathrm{~nm}$ in the presence of 2-propanol $\left(10^{-2} \mathrm{~mol} \mathrm{~L}^{-1}\right)$, a known $\mathrm{HO}^{\bullet}$ radical scavenger (Figure 1): $\mathrm{HO}^{\bullet}$ radicals are the major radical species present in the early stages upon irradiation of such solutions [16]. The initial 


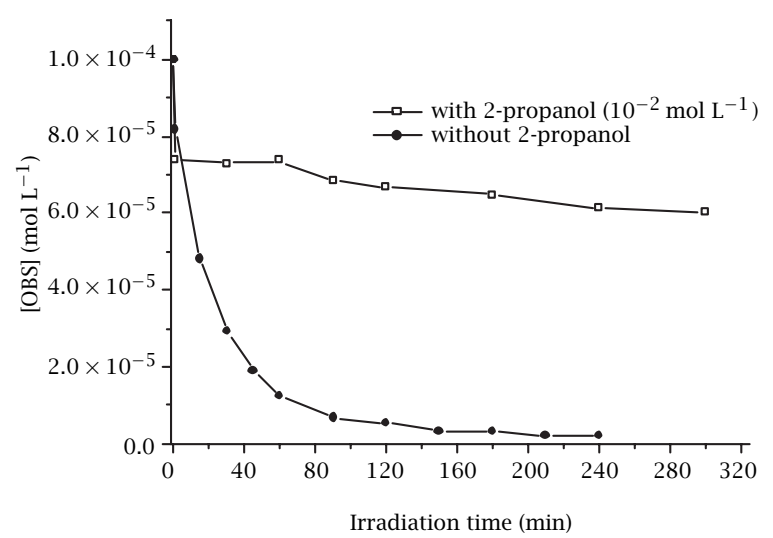

Figure 1. Decrease in OBS concentration upon irradiation at $365 \mathrm{~nm}$ with and without 2-propanol. OBS $(1.0 \times$ $\left.10^{-4} \mathrm{~mol} \mathrm{~L}^{-1}\right)$ and iron(III) $\left(3.0 \times 10^{-4} \mathrm{~mol} \mathrm{~L}^{-1}\right)$.

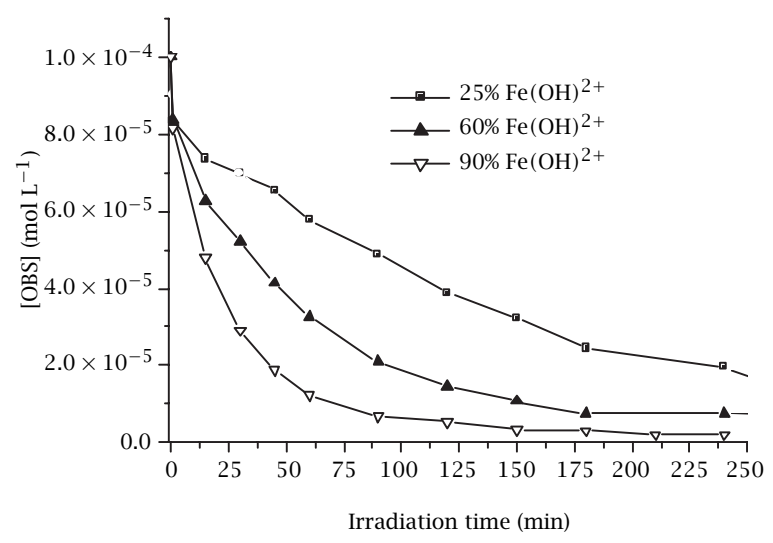

Figure 2. Degradation of OBS upon irradiation at $365 \mathrm{~nm}$ as a function of the monomeric species $\left(\mathrm{Fe}(\mathrm{OH})^{2+}\right)$ percentage. OBS $\left(1.0 \times 10^{-4} \mathrm{~mol} \mathrm{~L}^{-1}\right)$ and iron(III) $(3.0 \times$ $\left.10^{-4} \mathrm{~mol} \mathrm{~L}^{-1}\right)$.

disappearance of $20 \%$ of OBS due to the addition of iron(III), observed in both cases and even in the absence of light might be related to the formation of the complex [26].

3.2.2. Influence of the irradiation wavelength. In order to determine the influence of wavelength, solutions of OBS / iron(III) $\left(1.0 \times 10^{-4} \mathrm{~mol} \mathrm{~L}^{-1} / 3.0 \times\right.$ $10^{-4} \mathrm{~mol} \mathrm{~L}^{-1} ; \approx 90 \%$ of monomeric species) were irradiated at 313, 334 and $365 \mathrm{~nm}$. The initial quantum yields of OBS disappearance are collected in Table 1.

It appears that the efficiency of OBS disappearance is affected by the irradiation wavelength: the lower the wavelength, the more efficient the degradation is. This effect has to be related to the increase of the quantum yield of $\mathrm{HO}^{\bullet}$ radical formation when the excita-
Table 1. Influence of the irradiation wavelength on the initial quantum yields of OBS disappearance.

\begin{tabular}{l|ccc}
\hline Wavelength & $313 \mathrm{~nm}$ & $334 \mathrm{~nm}$ & $365 \mathrm{~nm}$ \\
\hline ФOBS & $0.160 \pm 0.005$ & $0.152 \pm 0.005$ & $0.075 \pm 0.002$ \\
\hline
\end{tabular}

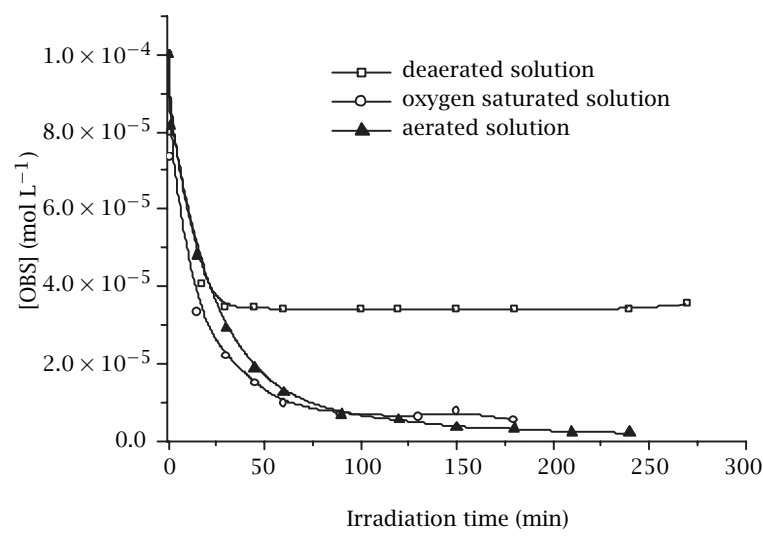

Figure 3. Degradation of OBS upon irradiation at $365 \mathrm{~nm}$ of OBS $\left(1.0 \times 10^{-4} \mathrm{~mol} \mathrm{~L}^{-1}\right)$ and iron(III) $\left(3.0 \times 10^{-4} \mathrm{~mol} \mathrm{~L}^{-1}\right)$ solution at various oxygen concentrations.

tion wavelength decreases. As it is precisely described in the literature, it is in agreement with the notion that ejection of $\mathrm{HO}^{\bullet}$ radical from the solvent cage requires kinetic energy [18]. As evidenced from Figure 1, the photoreactivity of the complex, non inhibited by isopropanol, is weak and can be neglected with respect to that of $\mathrm{HO}^{\bullet}$ radicals arising from $\mathrm{FeOH}^{2+}$ in the calculation of $\Phi$.

3.2.3. Influence of the monomeric species concentration. In this set of experiments, the percentage of $\mathrm{Fe}(\mathrm{OH})^{2+}$ species was taken as 90,60 and $25 \%$. The results show that the degradation of OBS is strongly affected by the $\mathrm{Fe}(\mathrm{OH})^{2+}$ percentage: the higher the percentage, the faster the degradation is (Figure 2).

This result is linked to the nature of iron(III) hydroxo species present in the solution, $\mathrm{Fe}(\mathrm{OH})^{2+}$ being the most photoactive species in terms of $\bullet \mathrm{OH}$ radical production $[17,18]$.

3.2.4. Influence of oxygen. Figure 3 shows the degradation measurements of OBS in aerated, deaerated and oxygenated solutions.

In the absence of oxygen, the initial OBS degradation was not significantly modified when compared to the results obtained in aerated solution. But after 30 minutes of irradiation, the degradation stopped. Such a phenomenon was often observed when dealing with iron(III) photoinduced degradation [16]. OBS degradation was not significantly increased by using oxygen saturated solution. So, if oxygen does not affect the first 


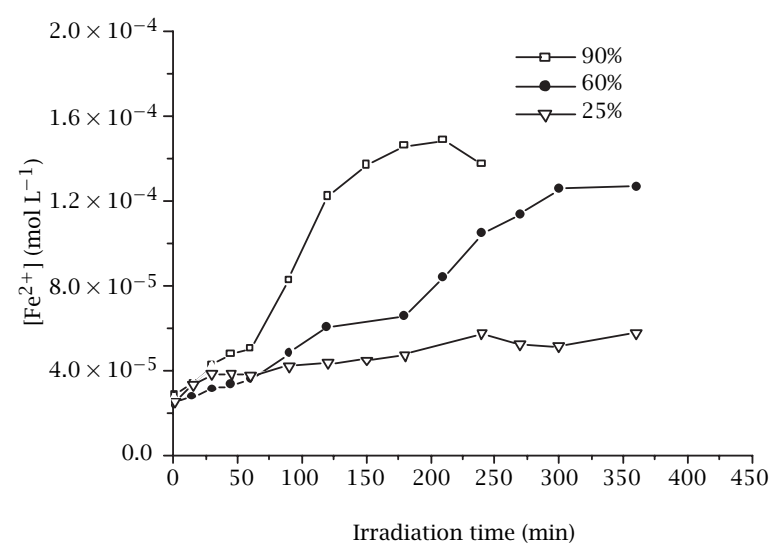

Figure 4. Iron(II) formation as a function of irradiation time (365 nm) of a mixture OBS $\left(1.0 \times 10^{-4} \mathrm{~mol} \mathrm{~L}^{-1}\right)$ and iron(III) $\left(3.0 \times 10^{-4} \mathrm{~mol} \mathrm{~L}^{-1}\right)$ at three percentages of $\mathrm{Fe}(\mathrm{OH})^{2+}$.

step of the degradation, its presence is necessary to pursue the degradation. The equilibrated oxygen concentration in water $\left(\cong 2.5 \times 10^{-4} \mathrm{~mol} \mathrm{~L}^{-1}\right)$ is sufficient to achieve the process.

3.2.5. Formation of iron(II). The formation of iron(II) was followed all along the irradiation at three percentages of $\mathrm{Fe}(\mathrm{OH})^{2+}$ (Figure 4).

In a general way, the higher the percentage in $\mathrm{Fe}(\mathrm{OH})^{2+}$, the higher iron(II) formation was. But the initial slow formation followed by an acceleration did not look like what was observed with the previously investigated systems: the fast iron(II) formation was observed from the very beginning $[16,19,20]$. The difference can be attributed to the possible interference of the thermal process again [26].

\subsection{Photoproducts identification. Numerous} photoproducts appear in the HPLC chromatogram of an irradiated solution (Figure 5). Some of them were identified by comparison with authentic sample: 4-carboxylicbenzene sulfonate, 4-acetylbenzene sulfonate and ethylbenzene sulfonate (EBS). The family of alkylbenzene sulfonates, propyl (PrBS), Butyl (BBS), pentyl (PeBS) ... was identified by comparison with the spectral characteristics of EBS: they have identical UV spectra. These results give evidence for a phenomenon of shortening of the alkyl chain. A similar phenomenon was already observed when dealing with alkylphenolpolyethoxylates but in that case, the shortening implied the ethoxylated chain with hydrogen atoms more labile than those on the alkyl chain [15].

Another family of photoproducts, labelled with “*”, also present identical UV spectra $\left(\lambda_{\max }=221\right.$ and $247 \mathrm{~nm})$. By considering the reactivity of $\mathrm{HO}^{\bullet}$ radicals on alkybenzene sulfonates, the hypothesis of hydrox- ylation of the aromatic ring can be put forward. Accordingly, this family would represent the hydroxylated derivatives of the alkylbenzenze sulfonates formed upon irradiation. All the results are in favour of a competitive attack of $\mathrm{HO}^{\bullet}$ on the alkyl chain. Moreover the nature of the two major photoproducts, 4-carboxylicand 4-acetylbenzene sulfonate, gives evidence for the main attack to occur on the carbon in $\alpha$ position. A proposed mechanism of OBS degradation is given in Scheme 1 . Any attempt to detect aldehydic derivatives failed contrary to what was observed in similar systems [15]. However, these photoproducts were only observed as minor photoproducts and the presence of 4carboxylic benzenesulfonate, arising from a further oxidation, can account for the absence of such derivatives.

In a general way, the global mass balance of the degradation and the nature of the observed photoproducts are not similar in the presence of iron(III) aquacomplexes or of $\mathrm{TiO}_{2}$. Two major parameters can account for the difference: iron redox properties and the adsorption at $\mathrm{TiO}_{2}$ surface.

3.4. Environmental significance. As already mentioned in the introduction, one of the aims of the present work was to test the efficiency of OBS removal from the water, when the degradation is photoinduced by iron(III). So, the process was tested by using solar light irradiation.

A mixture of OBS $\left(1.0 \times 10^{-4} \mathrm{~mol} \mathrm{~L}^{-1}\right)$ and iron(III) $\left(3.0 \times 10^{-4} \mathrm{~mol} \mathrm{~L}^{-1}\right)$ was exposed to natural sunlight during a sunny day (the average of solar irradiance during the experiment was $35 \mathrm{~mW} \mathrm{~cm}^{-2}$ ). OBS was totally degraded after $50 \mathrm{~min}$ of solar exposure, a period of time roughly four times lower than that necessary upon irradiation at $365 \mathrm{~nm}$. (Figure 6).

No significant difference in distribution of photoproducts was observed in comparison with the irradiation under artificial light at $365 \mathrm{~nm}$. Likewise what was observed in the previously investigated systems [15, 19], the process observed upon irradiation at $365 \mathrm{~nm}$ is representative of the phenomenon that takes place with solar light.

Total Organic Carbon (TOC) experiments were undertaken in order to make evidence for the complete mineralization of OBS. As shown in Figure 7, the mineralization of OBS $1.0 \times 10^{-4} \mathrm{~mol} \mathrm{~L}^{-1}\left(16.8 \mathrm{mg} \mathrm{L}^{-1}\right.$ of organic carbon) was achieved after 95 hours of irradiation.

The complete mineralization is obtained thanks to the oxidation of iron(II) into iron(III) resulting in the continuous formation of hydroxyl radicals as already described [27]. It is worth noting that the decrease in TOC roughly occurs after the disappearance of OBS (cf. insert) and can be attributed to a further attack of $\mathrm{HO}^{\bullet}$ on the aromatic ring, leading to the opening of the ring followed by the fast decarboxylation as already reported in the literature [13]. 


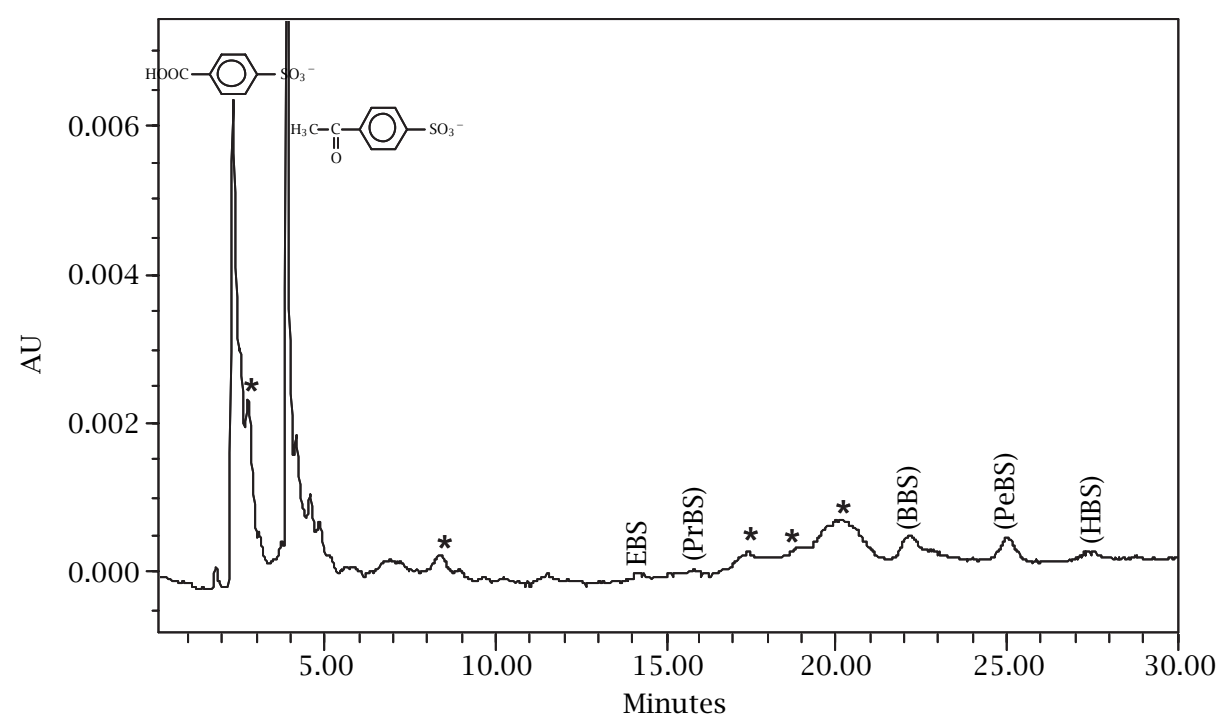

Figure 5. HPLC chromatogram of an irradiated solution (OBS $\left(1.0 \times 10^{-3} \mathrm{~mol} \mathrm{~L}^{-1}\right)$ and iron(III) $\left(1.0 \times 10^{-3} \mathrm{~mol} \mathrm{~L}^{-1}\right)$, $T=90 \min \lambda=365 \mathrm{~nm}$ ).

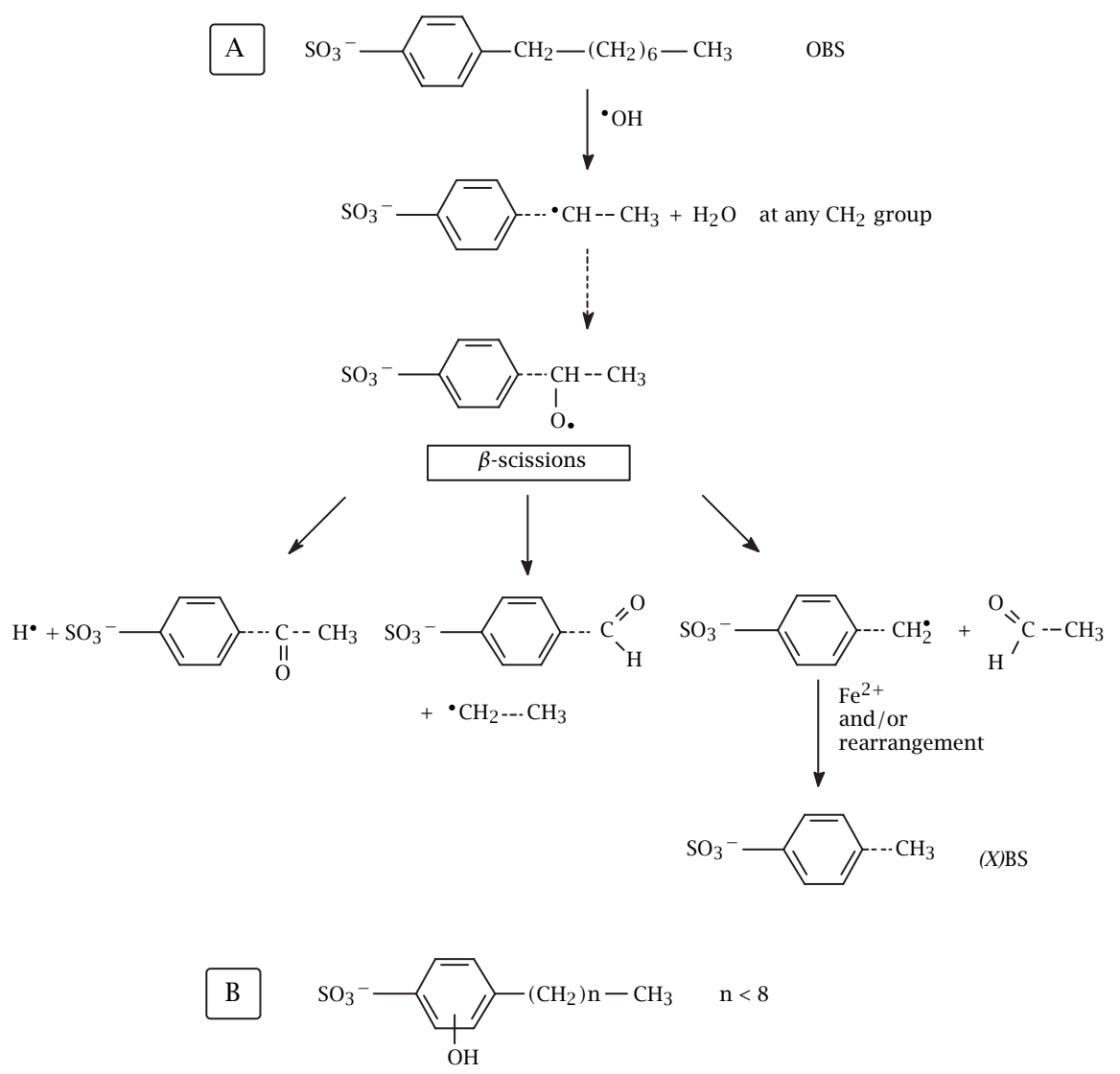

Scheme 1. Proposed mechanism of OBS degradation. 


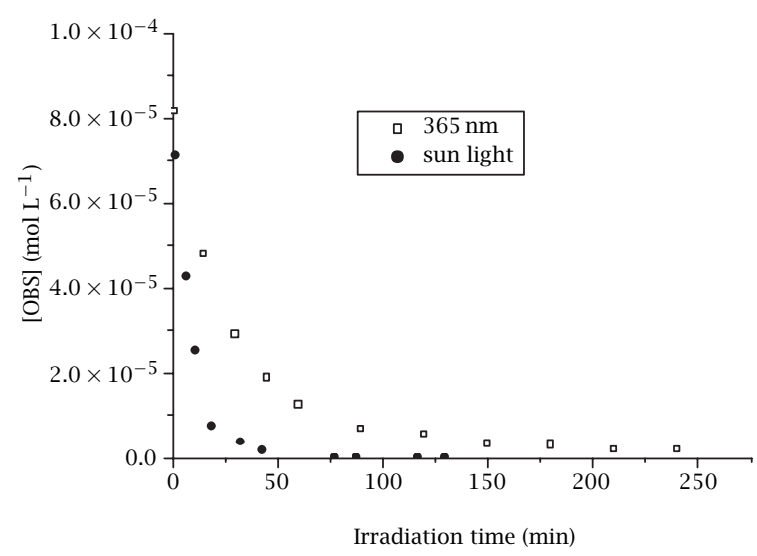

Figure 6. OBS degradation under sunlight or $365 \mathrm{~nm}$. OBS $\left(1.0 \times 10^{-4} \mathrm{~mol} \mathrm{~L}^{-1}\right)$ and iron(III) $\left(3.0 \times 10^{-4} \mathrm{~mol} \mathrm{~L}^{-1}\right)$.

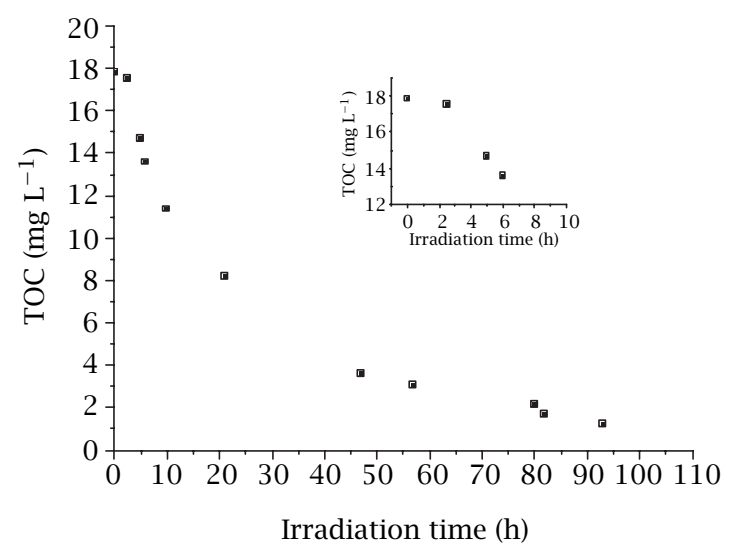

Figure 7. Time evolution of TOC values during irradiation time $(365 \mathrm{~nm})$ of $O B S\left(1.0 \times 10^{-4} \mathrm{~mol} \mathrm{~L}^{-1}\right)$ and iron(III) $\left(3.0 \times 10^{-4} \mathrm{~mol} \mathrm{~L}^{-1}\right)$ mixture.

\section{CONCLUSION}

These results are of importance as far as the removal process is concerned. OBS degradation photoinduced by iron(III) aquacomplexes appears to be efficient and interesting from an economical and ecological point of view. Actually, when considering the low concentrations in iron used in the process, the treated solution can be sent either directly to the natural environment after the complete mineralization or to the biological treatment after the disappearance of the aromatic compounds. This dual possibility brought by the iron(III) photoinduced degradation process represents a major advantage in terms of decontamination of polluted waters.

\section{Acknowledgments}

The authors thank J. F. Pilichowski for assistance in the structural characterization by NMR spectroscopy. They also thank the anonymous reviewers for helpful remarks.

\section{REFERENCES}

[1] P. Berth and P. Jeschke, Tenside Surfactants Dertergents 26 (1989), 75.

[2] W. De Wolf and T. Feijtel, Chemosphere 36 (1998), 1319.

[3] R. D. Swisher, Surfactant Biodegradation (second edition), Surfactant Science Series no. 18, Marcel Dekker Inc., New York, 1987.

[4] B. W. Topping and J. Water, Tenside Detergents 19 (1982), 164.

[5] H. A. Painter, The Handbook of Environmental Chemistry (O. Hutzinger, ed.), Springer Verlag, Berlin, 1992, p. 2.

[6] J. L. Berna and L. Cavalli, LAS. Facts and Figures, ECOSOL (European Center of Studies on LAB-LAS) report, a CEFIC Sector Group, Madrid, 1999.

[7] M. J. Schwuger, Anionic Surfactants-Biochemistry, Toxicology, Dermatology (C. Gloxhuber, ed.), Marcel Dekker, New York, 1980, p. 1.

[8] L. Meunier and P. Boule, Pest. Manag. Sci. 56 (2000), 1077.

[9] D. Vialaton, C. Richard, D. Baglio, and A. B. PayaPerez, J. Photochem. Photobiol. A: Chem. 119 (1998), 39.

[10] P. Mazellier, J. Jirkovsky, and M. Bolte, Pestic. Sci. 49 (1997), 259.

[11] G. V. Buxton, C. L. Greenstock, W. P. Helman, and A. P. Ross, J. Phys. Chem. Ref. Data 17 (1988), 513.

[12] H. Hidaka, K. Nohara, J. Zhao, E. Pelizzetti, and N. Serpone, J. Photochem. Photobiol. A: Chem. 91 (1995), 145.

[13] H. Hidaka, K. Nohara, K. Ooishi, J. Zhao, N. Serpone, and E. Pelizzetti, Chemosphere 29(12) (1994), 2619, and references therein.

[14] P. Mazellier, G. Mailhot, and M. Bolte, New J. Chem. 21 (1997), 389.

[15] N. Brand, G. Mailhot, and M. Bolte, J. Environ. Sci. Technol. 32 (1998), 2715.

[16] G. Mailhot, M. Astruc, and M. Bolte, Appl. Organomet. Chem. 13 (1999), 53.

[17] B. C. Faust and J. Hoigné, J. Atmos. Environ. 24A (1990), 79.

[18] H.-J. Benkelberg and P. Warneck, J. Phys. Chem. 99 (1995), 5214.

[19] G. Mailhot, M. Sarakha, B. Lavedrine, J. Caceres, and S. Malato, Chemosphere 49 (2002), 525. 
[20] G. Mailhot, A. Asif, and M. Bolte, Chemosphere 41 (2000), 363.

[21] J. G. Calvert and J. M. Pitts, Photochemistry, John Wiley and Sons, New York, 1966.

[22] W. H. Kuenzi, Die hydrolyse von eisen(III), PhD dissertation ETH no. 7016, Zurich, Switzerland, 1982.

[23] B. C. Faust and J. Hoigné, Atmos. Environ. 24A (1990), 79.

[24] R. J. Knight and R. N. J. Sylva, Inorg. Nucl. Chem. 37 (1975), 779.
[25] M. Chorro, Aggrégation et solubilisation dans les solutions d'ABS: étude par autodiffusion, $\mathrm{PhD}$ dissertation, Université de Montpellier, France, 1977.

[26] N. Debbache, G. Mailhot, K. Djebbar, B. Lavédrine, and M. Bolte, to be submitted.

[27] L. Poulain, G. Mailhot, P. Wong-Wah-Chung, and M. Bolte, J. Photochem. Photobiol. A: Chem. 159 (2003), 81. 


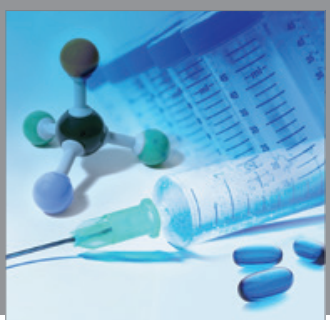

International Journal of

Medicinal Chemistry

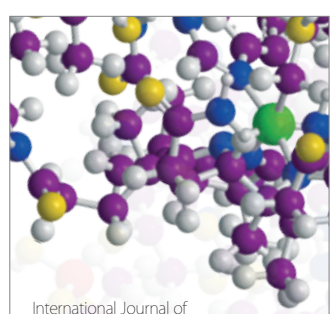

Carbohydrate Chemistry

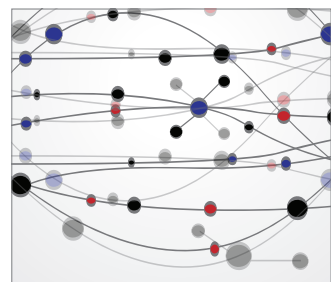

The Scientific World Journal
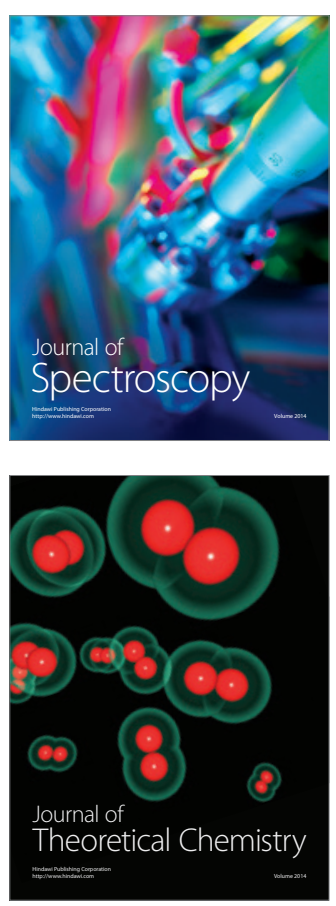
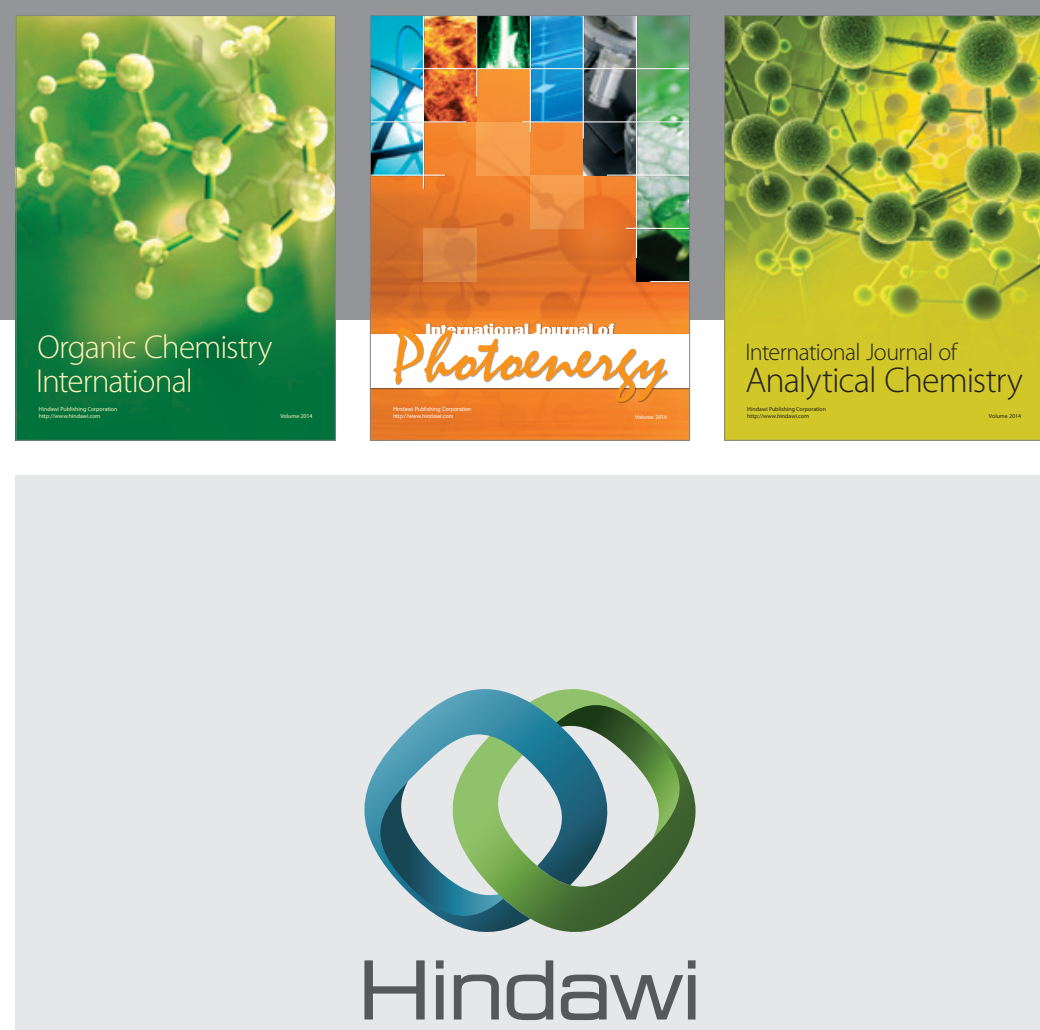

Submit your manuscripts at

http://www.hindawi.com


Journal of

Applied Chemistry
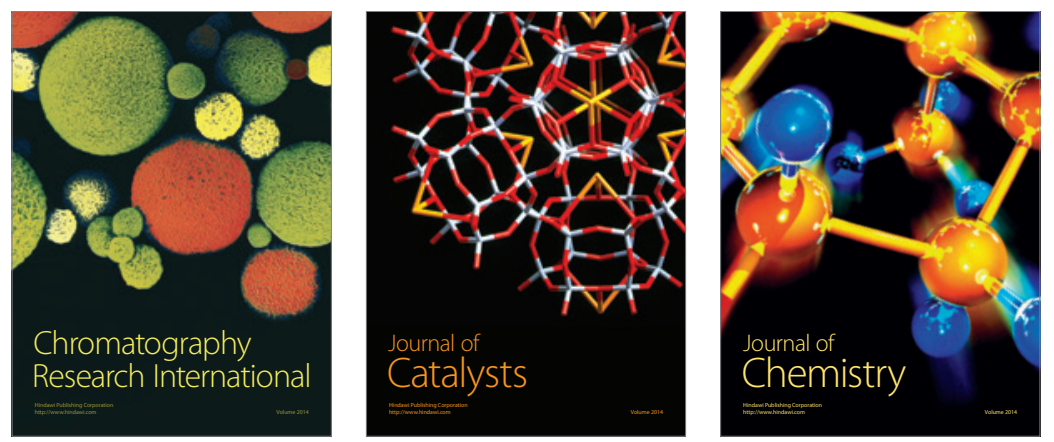
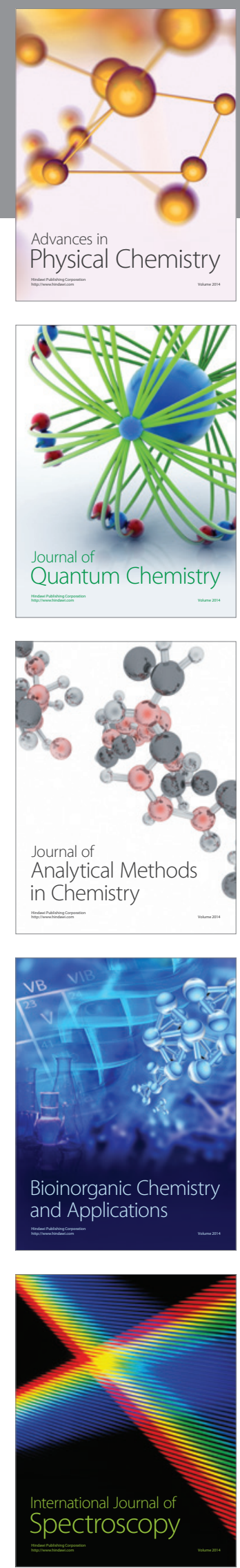